\title{
Correction to: TREM2 Attenuates A $\beta 1-42-$ Mediated Neuroinflammation in BV-2 Cells by Downregulating TLR Signaling
}

\author{
Huiping Long ${ }^{1}$ - Gang Zhong ${ }^{2} \cdot$ Chengzhi Wang $^{3} \cdot$ Jian Zhang ${ }^{1} \cdot$ Yueling Zhang $^{1} \cdot$ Jinglian Luo $^{1} \cdot$ Shengliang Shi $^{1}$
}

Received: 6 June 2019 / Accepted: 11 June 2019 / Published online: 14 June 2019

๑) Springer Science+Business Media, LLC, part of Springer Nature 2019

Correction to: Neurochemical Research https://doi.org/10.1007/s11064-019-02817-1

The article titled "TREM2 Attenuates A $\beta 1$-42-Mediated Neuroinflammation in BV-2 Cells by Downregulating TLR Signaling”, written by Huiping Long, Gang Zhong, Chengzhi Wang, Jian Zhang, Yueling Zhang, Jinglian Luo, Shengliang Shi, was originally published electronically on the publisher's internet portal (currently SpringerLink) on 27 May 2019 with open access.

With the authors' decision to step back from Open Choice, the copyright of the article changed on June 6 , 2019 to (C) Springer Science + Business Media, LLC, Part of Springer Nature 2019 and the article is forthwith distributed under the terms of copyright.
The original article has been corrected.

Publisher's Note Springer Nature remains neutral with regard to jurisdictional claims in published maps and institutional affiliations.
The original article can be found online at https://doi.org/10.1007/ s11064-019-02817-1.

Shengliang Shi

ssl_1964@163.com

1 Department of Neurology, The Second Affiliated Hospital of Guangxi Medical University, Nanning, Guangxi, China

2 Guangxi Medical University, Nanning, Guangxi, China

3 Department of Neurology, The Third Affiliated Hospital of Guangxi Medical University, Nanning, Guangxi, China 